\title{
Moral Psychology and the Intuition that Pharmaceutical Companies Have a 'Special' Obligation to Society
}

\author{
James M. Huebner
}

Received: 15 October 2012 / Accepted: 4 June 2013/Published online: 15 June 2013

(C) Springer Science+Business Media Dordrecht 2013

\begin{abstract}
Many people believe that the research-based pharmaceutical industry has a 'special' moral obligation to provide lifesaving medications to the needy, either free-ofcharge or at a reduced rate relative to the cost of manufacture. In this essay, I argue that we can explain the ubiquitous notion of a special moral obligation as an expression of emotionally charged intuitions involving sacred or protected values and an aversive response to betrayal in an asymmetric trust relationship. I then review the most common arguments used to justify the claim that the pharmaceutical industry has a special moral obligation and show why these justifications fail. Taken together, these conclusions call into question the conventional ideologies that have traditionally animated the debate on whether the pharmaceutical industry has special duties of beneficence and distributive justice with respect to the impoverished in dire need of their products.
\end{abstract}

Keywords Access to lifesaving medicines ·

Betrayal aversion - Moral intuition - Moral psychology ·

Pharmaceutical industry - Special moral obligation ·

Taboo trade-off theory

\section{Introduction}

There are...things...which we wish that people should do, which we like or admire them for doing, perhaps dislike or despise them for not doing, but yet admit that they are not bound to do; it is not a case of moral obligation; we do not blame them, that is, we

J. M. Huebner $(\square)$

Department of Philosophy, Suffolk University, 8 Ashburton

Place, Boston, MA 02108, USA

e-mail: jmhuebner@suffolk.edu do not think that they are proper objects of punishment (Mill 1861/2007, p. 42).

It has been argued that research-based pharmaceutical companies have 'special' moral obligations with respect to ensuring equality in access to their products (Banerjee 2006; De George 2005; Resnik 2001; Spinello 1992) that do not apply to industries that produce other types of goods or services (see e.g., Chang 2006). This idea is most commonly encountered in terms of a claim that companies in the pharmaceutical industry have a special duty ${ }^{1}$ to provide essential lifesaving drugs to developing nations, either freeof-charge or at some reduced rate relative to the cost of manufacture. The claim draws its inspiration, in part, from the Good Samaritan intuition that social agents are morally obligated to assist those in dire need when they can do so without sacrificing anything vital to themselves. Just as one is intuitively obligated to offer aid if one encounters a child drowning in a deserted shallow pond (Singer 1972), so the reasoning goes, the makers of lifesaving drugs are obligated to make them available when necessary to prevent needless death amongst the impoverished. It is important to note that this argument for a special moral obligation is distinct from standard theories of corporate social responsibility (Carroll 1999) in that the latter, while morally praiseworthy, are not generally considered obligatory (De George 2005, pp. 557-559; Porter and Kramer 2006, p. 82). ${ }^{2}$

\footnotetext{
1 The terms 'obligation' and 'duty' are considered synonymous herein and are used interchangeably.

2 According to Porter and Kramer (2006, p. 82), "[i]t is the nature of moral obligations to be absolute mandates...while most corporate social choices [e.g. corporate social responsibility initiatives] involve balancing competing values, interests and costs." I am grateful to the anonymous referee who brought this article to my attention.
} 
The claim that the pharmaceutical industry has a special moral obligation clearly resonates with the general public (Maitland 2002, pp. 452-453), does not seem especially controversial (Chang 2006, p. 465) and appears consistent with commonsense morality (see Jeske 2008). But is this because people are persuaded by the nuanced arguments of ethicists such as Resnik (2001) and De George (2005) who ground the supposed legitimacy of the argument for a special moral obligation for drug makers in the standpoints of beneficence and distributive justice? Or does this idea instead appeal more generally to emotion and moral intuition?

There are good reasons for questioning the causality of reasoning in the formation moral judgments. In recent years moral psychologists have been increasingly sympathetic to the moral philosophy of Hume, who referring to an innate moral sense famously wrote, "[r]eason is, and ought only to be the slave of the passions, and can never pretend to any other office than to serve and obey them" (1739/1985, p. 462). One prominent example is Haidt's (2001) Social Intuitionist Model. Haidt hypothesizes that emotionally laden intuitions, as shaped by social influences, frequently result in quick, authoritative moral judgments that are rendered, "without any conscious awareness of having gone through the steps of searching, weighing evidence, or inferring a conclusion" (ibid p. 818). Moral reasoning is then mostly relegated to ex post facto attempts to justify alreadyformed moral verdicts. Recent empirical studies have also demonstrated that laypersons broadly share strikingly nuanced intuitions about justice across a wide variety of liability and punishment issues (Robinson et al. 2007), although the reasons for such judgments may be not consciously accessible (ibid, p. 1685). Nevertheless, the degree of cross-cultural agreement on intuitions of justice suggests that this effect is a robust one (ibid, p. 1681).

The Social Intuitionist Model remains arguably the most important challenge to rationalism in the psychology of moral judgment (Sauer 2011, p. 708; Zyzik 2011, p. 220). Yet, the role of shared intuitions in assessing theories of special moral obligation, such as that popularly assigned to the pharmaceutical industry, has been largely ignored in the literature. This is surprising because such intuitions can lead to moral judgments that either defy rational justification (Haidt 2001, p. 817) or lead to disastrous consequences in public policy and public health decisions (Baron 1998).

In this essay, I have two primary objectives. First I argue that moral intuitions can explain the strong emotional appeal that underpins the popular claim that pharmaceutical companies have a special obligation of assistance towards those in dire need of their products (my main concern here is with life-saving medications rather than vanity or 'lifestyle' drugs, such as Viagra). Of course if moral intuitions provide an explanation for this claim they by no means by themselves offer a justification of it. My second objective therefore is to show how the arguments most commonly used to defend the claim that drug makers have a special duty of assistance all fail upon critical inspection. Taken together, these two conclusions call into question the conventional ideologies that have traditionally animated this debate.

These issues are both timely and important. There is no doubt that there is a widespread public belief that the pharmaceutical industry has been unfair in dealings with governments, regulators, healthcare practitioners, and the public in general (Angell 2004; Brody 2007; Santoro 2005; Koski 2005). Indeed, recent and widely publicized increases in government investigations and civil and criminal proceedings against pharmaceutical companies (e.g., Almashat et al. 2010; Angell 2004; Brody 2007) have begun to eclipse the positives aspects of this once esteemed industry in the public consciousness (Santoro 2005; Koski 2005). At the same time pharmaceutical industry executives continue to report a failure to comprehend how an industry responsible for saving so many lives could be held in such low public esteem (PricewaterhouseCoopers 2006). According to one, "[w]e find it quite incredible that we could be equated with an industry [tobacco] that kills people as opposed to cures them" (Harris 2004). Faced with public policy implications that include increased federal regulation, anti-industry political lobbying, higher regulatory barriers for marketing authorization, exclusion from formulary listings (preferred lists of drugs covered by prescription drug insurance programs), and patient/prescriber product boycotts, status quo inaction and rhetorical argumentation by the prescription drug industry no longer remains an option. Angell (2004), former Editor and Chief of the New England Journal of Medicine and outspoken industry critic, concedes, "[d] espite all its excesses, this is an important industry that should be saved - mainly from itself" (p. 237).

\section{Moral Intuitions About Social Obligations}

\section{The Most Objectionable of All Taboos}

This is not like lipstick or perfume. These are drugs that people need to live... (Lewis and Pear 1994).

Contemporary social relational theory suggests that we should expect people to be extremely resistant to transactions that require trade-offs that contravene deeply held sacred or protected values (Fiske and Tetlock 1997; Baron and Spranca 1997). For example, it is considered morally impoverishing to attach a finite monetary value to things one is normatively obligated to treat as infinitely important (Tetlock et al. 2000; Fiske and Tetlock 1997), such as one's 
marriage, children, friendships, or fidelity. This phenomenon is based on the notion of constitutive value incommensurabilities (Raz 1986; see also Hsieh 2008) that arise whenever people believe that entering one value into a trade-off calculus with another undermines the sanctity of one of the two values (Fiske and Tetlock 1997; Tetlock 2002). Trade-offs of this type are intuitively judged as forbidden or taboo (Fiske and Tetlock 1997) such that, "merely making explicit [their] possibility...weakens, corrupts, and degrades ones moral standing" (ibid, p. 256).

Human life and health are generally foremost among the things considered absolute and infinitely valuable —in effect sacred. The claim that the pharmaceutical industry has a special moral obligation may therefore be explained in part as a response to a shared, subconscious perception of a taboo trade-off: specifically a trade-off between any individual's posited right to access a desperately needed lifesaving drug and the protection of intellectual property rights claimed by the firm that discovered and developed that drug. Indeed, the extremist position maintains that lifesaving drugs are simply too inviolable to be subject to market pricing; to limit their access to only those individuals with the ability to pay, it would seem, comes uncomfortably close to the notion of commodifying human life itself. This explanation is supported by the idea that there exists an inalienable right to health-a concept that acquired widespread currency in the post-World War II human rights movement (Pillay 2008) ${ }^{3}$ as well as the industry's intrinsic (and well-publicized) profitability and close association with other elements of human healthcare management that are conventionally regarded as humanitarian in nature (McGraw et al. 2011; Weber 2001). Simply put, "[i]t is seen as indecent to...[make] money (and what appears like a lot of it) from desperately ill people" (Maitland 2002, p. 452).

Fiske's (1992) influential social relational theory identifies a ranked continuum of just four elementary psychological models or domains that organize all of our social relationships:
The claim for a special moral obligation for prescription drug makers is hypothesized here to be grounded in a tradeoff between the two models that represent the ideological extremes of Fiske's continuum:

Communal Sharing (CS): In which social exchanges are based on group membership and people may contribute to, or take from a collective commons based on ability and need.

Market Pricing (MP): In which social exchanges are organized with reference to ratios of a single utility metric-typically money. People pay or exchange for goods or services in proportion to the value of what was received.

Responses to explicit domain trade-offs include an aversive state of arousal, moral outrage, that is characterized by anger, contempt, and a desire for punishment (Fiske and Tetlock 1997; Tetlock 2002). The intensity of this response varies in relation to both the direction and distance between the domains transgressed, with the most severe judgments reserved for transactions that contravene the 'three full steps' in the direction from Communal Sharing to Market Pricing (Fiske and Tetlock 1997; McGraw et al. 2011). This suggests that pharmaceutical executives should expect public resentment-even outright hostility - when presenting people with trade-off situations that appear to cross normative bounds (see, e.g., Berenson 2006; Experts in Chronic Myeloid Leukemia 2013).

Recent empirical evidence supporting this hypothesis been provided by McGraw et al. (2011), who found that consumers were indignant when presented with profitbased justifications for pharmaceutical market pricing strategies, but not when the same rationalizations were offered for software companies [another industry heavily dependent on Research and Development (R\&D)]. Consistent with other survey research (PricewaterhouseCoopers 2006), these same authors also found that the consumer distress effect disappeared when the drug was specified as a 'lifestyle' or vanity product instead of a need-based one. ${ }^{4}$

Communal Sharing $\rightarrow$ Authority Ranking $\rightarrow$ Equality Matching $\rightarrow$ Market Pricing

\footnotetext{
3 This timing broadly parallels the ascendancy of the modern pharmaceutical industry (see Hilts 2003). It is tempting to speculate that the contemporary difficulty in explicating a reliable "moral calculus needed...[to] tell a pharmaceutical company how to allocate its revenues among subsidizing care for the indigent today, developing cures for the future, and providing dividends to its investors" (Porter and Kramer 2006, p. 82), might be explained in part by historical institutionalism and path dependence. A detailed discussion of these topics, however, is beyond the scope of this essay.
}

\footnotetext{
${ }^{4}$ One potential criticism of this study is that the "lifesaving" intervention indicated in the study instrument questionnaire was defined as an "anti-cholesterol" drug. While these types of medications are widely prescribed for preventing heart attacks and strokes, they are categorically distinct from therapeutic interventions that are needed to prevent imminent death. In this essay, the term "lifesaving" is restricted to the latter definition.
} 
Information Asymmetry, Corporate Misconduct, and Betrayal Aversion

When there is uncertainty, information or knowledge becomes a commodity...the value of information is frequently not known in any meaningful sense to the buyer; if, indeed, he knew enough to measure the value of the information, he would know the information itself. But information, in the form of skilled care, is precisely what is being bought from most physicians and, indeed, from most professionals... and there is an element of trust in the relation (Arrow 1963, pp. 946-949).

Consumers of healthcare are generally poorly positioned to judge the utility that may be derived from any prescription pharmaceutical product or class of products (Maynard and Bloor 2003). The specialist knowledge of highly skilled intermediaries - physicians - is typically required to diagnose and predict the likely medical outcomes from any therapeutic intervention (ibid, see also Hardwig 1985). Physicians, in turn, depend on the outcomes of clinical trials, mostly sponsored by the pharmaceutical industry, for the overall benefit-risk profile that provides the basis for physician labeling of a drug for its intended medical and commercial use. According to Maynard and Bloor (2003), "[b]ecause of this information asymmetry, the consumer and the supplier initiate an agency relationship, with the doctor helping the patient to make choices" (p. 532, emphasis added). Implicit in this agency relationship is an element of dyadic trust, in this case negotiated by physician intermediaries on behalf of the pharmaceutical suppliers (see Zucker 1987, p. 454). ${ }^{5}$ Yet, as noted above, the pharmaceutical industry has recently been subject to widespread public condemnation on the basis of questionable business practices. A brief sampling of alleged abuses include, but are not limited to, overcharging government health programs, kickbacks to healthcare service providers, unlawful promotional tactics, disease mongering [widening the definition of treatable 'illnesses' specifically to grow markets for prescription drugs (Moynihan et al. 2002)], collusive and other anticompetitive practices, and deliberately concealing unfavorable research study results in order to obtain a commercial advantage (Almashat et al. 2010; Santoro 2005; Angell 2004, 2008; Brody 2007; Clark 2003; Pyke et al. 2011). This is an abysmal record of behavior for any industry, but especially for one so closely allied with human healthcare. Consequently, I suggest here that the claim that the pharmaceutical industry has a special moral obligation is reinforced by a betrayal aversion response (Koehler and Gershoff 2003): a subjective, subconscious

\footnotetext{
5 See Angell (2004) and Brody (2007) for recent discussions on the influence the industry has over physician prescribing habits.
}

desire for retribution, punishment, and justice stemming from an intuitive asymmetric trust violation. Consider here, for example, the consumer outcry following the withdrawal from the market of Vioxx (rofecoxib), a drug widely prescribed for arthritis pain from 1999 until Merck recalled it 2004 (Merck 2004) after the drug was found to increase the risk of heart attack and stroke. As early as 2000, there was strong evidence that Vioxx was associated with a fourfold increase in cardiovascular side effects compared with Naprosyn (naproxen), a competitor drug (Bombardier et al. 2000). Nevertheless, Merck argued that this difference could be explained by the cardioprotective effects of Naprosyn (a claim unsubstantiated by any clinical data known at the time) (Choo 2008; Karha and Topol 2004). Despite mounting epidemiological evidence demonstrating that Vioxx significantly increased the risk of cardiovascular death, "Merck opted to ignore the warning signs and [continue to] market Vioxx to consumers, including those with cardiovascular disease" (Karha and Topol 2004, p. 934). Ironically, the company finally withdrew the drug after a Merck-sponsored trial designed to test whether Vioxx could prevent the recurrence of colon polyps showed that the drug doubled the risk of heart attack or stroke (Bresalier et al. 2005). What makes cases like this particularly striking is the idea that organizations that have a professional obligation to ensure that the medications that they produce are both safe and effective sometimes themselves become agents of the very types of harms they are supposed to protect us against (Koehler and Gershoff 2003).

The foregoing discussion is not intended to provide an exhaustive list of the explanatory mechanisms supporting the claim that the pharmaceutical industry has a special moral obligation to aid those in dire need of its products. I submit that there may be others yet to be considered. Nevertheless, both the taboo trade-off and the betrayal aversion hypotheses are sufficient to suggest a primary role for affect and emotion in the claim for a special moral obligation for prescription drug makers; that is it can be said to be more a product of a shared moral intuition than moral reasoning (cf. Robinson et al. 2007). Indeed, this intuitional nature can help explain the salient features surrounding this particular claim in the literature, such its widespread acceptance, resistance to reasoned persuasion, and "raw perception of rightness" (Baron 1998, p. 5).

Nevertheless, those in the business of assigning moral obligations must do more than be able to explain them; obligations require justifications.

\section{Can We Justify a 'Special' Moral Obligation for the Pharmaceutical Industry?}

In sympathy with Mill (1861/2007), we can identify the morally obligatory with that which we could reasonably 
compel a moral agent to do, or to rightfully condemn or blame for failing to do. Wolf (2009) has argued that, insofar as we restrict the concept of moral obligations to this use, we should accept them as being inculcated by the expectations or demands of society (see also Baron 1998, p. 179). While it has been argued that there are differences in the definition of what constitutes the proper meaning of 'society' (Wolf 2009), I want to bracket them here and assume that we can agree on the commonsense view that moral obligations derive their legitimacy from the same conception of 'society' as that which has the authority to demand compliance with a given set of legal obligations (Durkheim 1912/1995, p. 422; see also Greenwald 1973). To be sure, legal obligations are unquestionably distinct from moral obligations. My point here is only that the latter can best be understood as derived from the same ontological authority.

With this background, we can now ask: what are the most common arguments used to support the claim that companies in the pharmaceutical industry have a special moral obligation to make their products available to the impoverished? ${ }^{6}$

\section{Intentional Agency and Proximity}

According to this line of reasoning, research-based pharmaceutical companies have special moral obligations, "because of the field they have freely chosen, because they are related to health care in a way others are not, because they have the [drug development] expertise that others lack, and because they make their living or profit from health-related activities," (De George 2005, p. 555). In other words, they operate as intentional agents, not simply social bystanders, in circumstances that directly impact the sick, suffering and dying. In short, like the passerby in the case of the drowning child, manufacturers of lifesaving products are simply in the best position (or 'proximity') to help.

This is a deceptively attractive argument. Yet, there are a number of objections that can be offered here. First, consider the notion of intentional agency-the idea that pharmaceutical companies deliberately place themselves in a position within the chain of human healthcare such that they have a special obligation of beneficence. This view essentially conflates the divergent social roles of communally focused medical care ('ministering to the sick') with that of a private sector industry. Indeed, when explicitly asked, most people do appear to understand that the pharmaceutical industry is fundamentally profit-driven (Kaiser 2005; McGraw et al. 2011; PricewaterhouseCoopers 2006).

Second, as others have noted (Chang 2006) for a product to be categorized as lifesaving it need only satisfy the

\footnotetext{
${ }^{6}$ See also Chang (2006, pp. 472-476) and Maitland (2002, pp. 459-470) for other surveys of these familiar arguments.
}

criterion that it would prevent death when provided to those who necessarily require it to survive. By this same logic, any number of products could be construed as lifesaving depending on the specific circumstances defining the precise 'condition of need' (e.g., famine, drought, war, etc.). Third, there are other social agents involved in human health care management for whom the proximity theory would appear to apply more directly - the most obvious example here is the State (United Nations 2008; Lehman 2003; Leisinger 2005; De George 2005; Banerjee 2006; Greve 2008), which importantly differs from corporations in that its legal powers are assumed directly. While it could be argued that a State's capacity to make lifesaving drugs available to its population is fundamentally limited by its jurisdictional scope in a way that modern transnational corporations are not (Greve 2008), it still does not follow that the latter are thereby subject to special moral obligations in the service of public, rather than private, interests. ${ }^{7}$ Lastly, to what extent does the commercial pharmaceutical industry have a special moral obligation to provide lifesaving medications to impoverished citizens of a country whose government chooses to spend significantly more of its scarce resources on weaponry or luxury goods rather than on health care? (Leisinger 2005, p. 581). ${ }^{8}$

Ultimately, then, proponents of intentional agency and proximity claims fail to demonstrate that the sick and impoverished are uniquely dependent on the pharmaceutical industry alone. This position might therefore be best condemned as "...compassion on the cheap. It makes moral free-riders out of the rest of us" (Maitland 2002, p. 460). ${ }^{9}$ In other words, assuming that we all have a collective moral duty to aid the impoverished, it is not a shortage of lifesaving drugs that is at issue, but rather the lack of sufficient resources required to purchase and distribute those drugs.

\section{Reciprocity}

This argument is based on the benefits that the researchbased pharmaceutical industry receives from sources

\footnotetext{
7 Indeed, the plurality of ethical systems and their underlying values encountered in the global marketplace would make this pragmatically challenging at best.

8 "On average, African countries spend only 5 percent of total government expenditures on health. This is particularly disturbing considering that HIV/AIDS is widespread among its general population" (Fan and Rao 2003, p. 8). See also Morel (2003), p. S36, for countries that spend disproportionately more on military expenditures than public health.

${ }^{9}$ Regarding free riding, the United States Supreme Court has maintained that, "The Fifth Amendment's guarantee that private property shall not be taken for public use without just compensation was designed to bar Government from forcing some people alone to bear public burdens which, in all fairness and justice, should be borne by the public as a whole." (Armstrong v. United States, 364 U.S. 40, 1960). See also (Maitland 2002), note 63 at p. 476.
} 
supported by public funds, such as the National Institutes of Health (NIH) and other government agencies (Angell 2004; Banerjee 2006; Chang 2006; Maitland 2002). ${ }^{10}$ Critics contend that the public essentially pays twice for prescription drugs developed with assistance from the federal government: once through taxation and again at the pharmacy (The New York Times 1994, Maitland 2002). Under the reciprocity principle, then, the industry possesses a consequential moral obligation to the constituency that provides this financial support.

While many people claim to support this view, it is not at all clear that the use of public funds in the process of developing new pharmaceutical drug products represents a bad bargain for taxpayers in general. ${ }^{11}$ Pharmaceutical $\mathrm{R} \& \mathrm{D}$, a process intrinsically dependent upon repeated cycles of trial and error, is notoriously risky, time consuming, and expensive. In addition, even after accounting for the aid of publicly funded research, "the applied science of drug development and clinical refinement of compounds occurs almost exclusively in the private sector," (Zycher and DiMasi 2008). ${ }^{12}$ Indeed, the very existence of government subsidies, such as the U.S. Orphan Drug Act, which encourages drug makers to develop therapies for life-threatening diseases in instances where markets are otherwise small, suggests that we already

\footnotetext{
${ }^{10}$ Recently, Sampat and Lichtenberg (2011) reported an even greater role for the relative importance of 'indirect' public funding in pharmaceutical drug development, using patent citation data as a surrogate indicator for public sector influence. In their analysis of 379 drug approvals (1998-2005), approximately $25 \%$ cite at least one at least one publicly funded patent (p. 335). Nevertheless, we should be circumspect in the interpretation of these findings. The sampling methodology used by the authors presupposes that citations are a reliable proxy for the influence of publically funded inventions on pharmaceutical drug development. This is problematic for at least two reasons. First, the disclosure of previous patents related to research findings can be viewed as a protective strategy to avoid, "strong penalties... and the invalidation of the patent" (ibid p. 334), and do not necessarily reflect actual influence. Second, investigational scientific research is not a solitary enterprise but instead is fundamentally derivative and dependent upon intellectual inheritance.

${ }^{11}$ See Cutler et al. (2006) who concluded that increases in medical spending in the period between 1960 and 2000 provided a reasonable return on investment. See also Cockburn and Henderson (1996) on the misleading, but otherwise widespread belief that scientific information transfers between the public and private sectors only benefits the latter.

12 The actual costs involved in bringing a drug to market are widely disputed. For example, Herper (2012) estimated R\&D expenditures averaging up to $\$ 6.2$ billion dollars for each drug approved once the cost of failure is factored in-a figure that was promptly disputed by Light and Warburton (2012). While I acknowledge the inherent unreliability in R\&D cost estimates, principally due either to the inclusion or omission of a number of underlying variables, I am nevertheless sympathetic here to the conclusions of Reisel and Sama (2003, p. 372) who write, "...[E]ven if the costs are inflated, few would dispute that the cost for bringing drugs to market is very high."
}

accept the legitimacy and practical need of subsidies and financial incentives. ${ }^{13}$

Chang (2006) invokes what she calls a symmetry property of coherent moral theories to refute the claim that drug makers have a special obligation for reciprocity:

It would be incoherent for utilitarians to say that some people should act to maximize happiness while others need not do so. Kantians would be regarded as unreasonable if they held that some rational beings were bound by the categorical imperative, but others were not...As with moral theories applied to individuals, the symmetry property is necessary for the coherence of corporate theories of obligation (ibid, p. 471).

Since industries from aerospace to textiles are supported by public sector funding, this criterion alone fails to establish a special moral obligation of reciprocity for the pharmaceutical industry. ${ }^{14}$ Furthermore, as implied above, any such duty would logically be limited to the constituents of the particular society supplying the funding (ibid)—not the impoverished nations in need of lifesaving medicines and for whom this argument is commonly cited.

\section{Intellectual Property Forgiveness}

What is the use of discussing a man's abstract right to food or medicine? The question is upon the method of procuring and administering them. (Burke 1790/ 1987, p. 53.)

Proponents of the Intellectual Property Forgiveness theory claim that pharmaceutical companies could effectively release intellectual property rights in developing and

\footnotetext{
13 The law itself explicitly recognizes the need for such subsidies in situations where, "there is no reasonable expectation that the cost of developing and making available in the United States a drug for such disease or condition will recovered from sales in the United States of such drug" U.S. Orphan Drug Act (SEC. 536(2)(B)). http:// www.fda.gov/regulatoryinformation/legislation/federalfooddrugand cosmeticactfdcact/significantamendmentstothefdcact/orphandrugact/ default.htm. Variants of the U.S. Orphan Drug Act have now been adopted by a number of other countries (De George 2005, p. 560).

${ }^{14}$ I have been asked by one anonymous referee to consider here that the mission of firms in the aerospace and textile industries differs considerably from that of companies in pharmaceutical industry-a point that I readily concede. However, I believe that my argument remains sound for at least two reasons, both of which I have touched upon previously. First, the economic rationale for the public funding of scientific research is based on the belief that private industry lacks adequate incentives to invest in certain types of basic research (Cockburn and Henderson 1996, p. 12725; Maitland 2002, p. 469, see also Footnote 13). Second, as I have argued above, the fact that private sector pharmaceutical companies deliberately develop products aimed at saving lives, does not by itself confer any special obligations of beneficence or justice that do not apply to other industries or social agents in general. This leads again to the free-rider problem.
} 
underdeveloped nations with little, if any, net effect to their bottom lines (i.e., since these countries do not contribute to it anyway) (Chang 2006; Greve 2008). This would then allow these nations to copy and distribute lifesaving medicines at a lesser cost (at some reduced rate relative to the cost of manufacture) that would make them accessible to their indigenous populations.

This argument initially appears attractive from a utilitarian perspective. However, there are serious objections that can be raised here as well. First, the symmetry property again applies (Chang 2006, p. 474); surrendering patent rights for agricultural applications of gene technology, for example, could save untold numbers of lives in impoverished nations struggling to feed their constituent populations. Drug makers therefore cannot be singled out on this basis for any special duty. Second, the risks of both piracy and parallel trade ["the exportation and importation of products through distribution channels that are other than those authorized by the owner or licensee of a patented...product" (Bale 1998, p. 637)] make this proposal pragmatically challenging. For example, what incentive would a company have to assume the risk, time, and expense necessary to develop a medication for a rare, lifethreatening illness affecting predominantly impoverished nations if that drug is at high risk for appropriation and illicit copying by rogue States (Maitland 2002)? In the case of parallel imports, at least one European study has demonstrated that "[p]atients do not benefit directly from parallel trade...[and] manufacturers incur a significant loss of business in destination countries...without necessarily increasing societal welfare" (Kanavos et al. 2004, p. 135.) The hazards of inadequate quality control in the manufacturing, packaging, storage, and handling resulting from the absence of established regulatory control safeguards could have critical public health consequences in both instances as well (Bale 1998). ${ }^{15}$ Finally, any serious attempt to implement such a strategy would require adequate local capacity and technical skills in addition to satisfactory healthcare and medicine distribution infrastructures (Leisinger 2005); this is simply not realistic for many developing nations. ${ }^{16}$

\section{Regulated Profit Margins}

This argument holds that profit margins for pharmaceutical companies are amongst the highest for any industry and that a tremendous amount of these profits are spent on excessive, often allegedly corrupt promotional activities. These excess funds could be more responsibly reinvested

\footnotetext{
15 See, for example, Nayyar et al. (2012).

16 For detailed discussion of some of these considerations, see Hasan and Wanyanga (2010), Rugumambaju and Kutyabami (2010), Wambebe and Ochekpe (2011), and Chitemerere (2011).
}

into the R\&D of novel therapies for unmet medical needs or even rightfully appropriated for humanitarian ends.

Objections to this popular view are similar to those offered for the arguments for intentional agency and proximity above. The fact that the pharmaceutical industry has high profit margins fails to distinguish it from other financially lucrative industries. In 2011, for example, mining and crude-oil production, software, and networking/communications equipment industries all averaged higher profit margins than the top 12 pharmaceutical companies listed in the Fortune 500 (Fortune Magazine 2011). This again fails to demonstrate any type of unique dependence of the sick and the poor on the pharmaceutical industry alone, and hence leads again to the seemingly intractable free-rider problem mentioned above. In addition, even if such a distinction could be made, it does not logically follow that the moral debt in question must be repaid in terms of lifesaving medications (Chang 2006); a donation to any legitimate charitable organization, such as Habitat for Humanity for example, would satisfy any such obligation. Lastly, and perhaps most importantly, if society appropriates the profits that incentivize both individual and corporate investors, then drug makers, particularly the startup biotech companies that provide much of the innovation in modern drug development, would need to pursue other lines of business in order to ensure their continued economic survival (Maitland 2002). ${ }^{17}$ Otherwise, investors would naturally seek alternative investment vehicles unencumbered by any 'special' liability (ibid, Adams and Osho 2006).

I have argued that the claims commonly used to support a special moral obligation for prescription drug makers are unjustified. It follows, then, that we have no legitimate justification for compelling pharmaceutical companies to be more socially responsible when compared with any other industryor social agent in general-with respect to ensuring equality in access to lifesaving medications (see also Chang 2006). Indeed, unless we are prepared to abandon any principle of impartiality or fairness in the assignment of special moral obligations, all members of society share in this particular obligationregardless of how reluctant we may be to accept it.

\section{General Discussion and Concluding Remarks}

[T] he pharmaceutical industry occupies an unenviable position near the bottom of the public's affections. Ask people why, though, and they may find the reasons for their disdain hard to pin down. (The Economist 2012)

\footnotetext{
17 According to Taurel (2005, p. 334) this, "has happened before in the United States...[i]n the 1960s, in the aftermath of the notorious Kefauver hearings, we saw pharmaceutical companies rapidly diversifying into all sorts of business lines... [t]hat's how [Eli] Lilly came to be, for a number of years, the owner of Elizabeth Arden cosmetics."
} 
In her 2006 paper, "Who's in the Business of Saving Lives?" Chang (2006) conceded that the intuition that drug companies have a special moral obligation to provide the impoverished with lifesaving medications is so widely accepted amongst the general population that it may be practically impossible to fully abandon the claim (p. 477). How can we explain the discrepancy between an obligation that cannot be justified and the apparent strength of the underlying intuitions supporting its claims?

On present evidence, I believe that the answer to this question can be found in the field of moral psychology. In the first half of this essay I argued that emotionally charged intuitions can provide a sufficient explanation for the popular assignment of a special moral obligation to the research-based pharmaceutical industry. It should be emphasized that this is a descriptive claim-it does not suggest how people ought to make judgments about moral agency and moral obligations towards the impoverished in need of lifesaving drugs. Instead, it explains why such judgments are so widespread and held with such strong conviction. Support for this idea can be found in recent empirical data showing that human intuitions of justice are, "deep, predictable and widely shared" (Robinson and Kurzban 2007, p. 1892), but not necessarily the product of conscious deliberation or self-reflection (Robinson et al. 2007). To explain this phenomenon, Robinson and colleagues (ibid, pp. 1685-1686) point to Haidt's work on 'moral dumbfounding' (Haidt 2001, p. 817) in which people report strong intuitions about things that appear be ideologically off-limits or taboo, such as private consensual non-reproductive incest between siblings, but are unable to provide rational justifications to support their convictions. When pressed, individuals will often proclaim to 'just know' something is wrong, stubbornly clinging to their moral judgments without being able to explain why (ibid).

The arguments made in this essay suggest that the same principle is operating here. The research-based pharmaceutical industry has undertaken the morally praiseworthy responsibility of discovering and developing drugs to treat life-threatening medical conditions. Yet, at the same time the industry fails to account for society's shared intuitions about beneficence and distributive justice with respect to access to lifesaving medicines. This inevitably is perceived as failing to adequately contribute to the public good. Ultimately, this helps explain why a common ground on the obligations of the pharmaceutical industry to the impoverished in need of lifesaving drugs remains so elusive.

There are important implications that follow this conclusion. For example, such intuitions are especially resistant to change and manipulation (Robinson and Kurzban 2007; Robinson et al. 2007; see also Shirley and LanganFox 1996, p. 564 and Dorfler and Ackermann 2012, p. 547) and are doubtlessly reinforced by the well-known phenomenon of confirmation bias (Baron 1998). This observation suggests that the conventional pharmaceutical industry claim that its poor public image results from a fundamental failure to educate the layperson about the economic realities of commercial R\&D (see, e.g., Koroneos 2009; PricewaterhouseCoopers 2006; Taurel 2005) is profoundly misguided. ${ }^{18}$ Indeed, as noted above industry executives and spokespersons should not be particularly surprised that the industry is held in such low esteem by the general public. People should, and apparently do, viscerally reject any notion that that portrays human life as commodity subject to the vagaries of market exchange.

This conclusion should not be taken to imply that intuitions of this sort are immutable. Rather, we must be realistic about the financial and social costs that may be required to change them (Robinson and Kurzban 2007; Robinson et al. 2007). Future research might examine the psychological mechanics underlying shared intuitions about moral agency and moral obligation as applied to the prescription drug industry. It is hoped that this research will enable a more productive dialog between the industry, policy makers, international aid agencies, state governments, and all others interested in providing the impoverished with access to desperately needed lifesaving medicines.

Finally, what I have said here in no way denies that the pharmaceutical industry remains in dire need of ethics reform. There is no question that there exists a nearly universal moral outrage in response to the industry's deceptive and unlawful business practices and it remains an open question whether prescription drug makers can effectively regulate themselves in accordance with societal expectations. For industries that operate within the arena of human health care management, this means relying on far more than compliance alone (Weber 2001).

Acknowledgments The author is currently employed by the pharmaceutical industry. He is not a spokesperson for the industry and the views expressed in this material are entirely his own. Jeppe von Platz, Michael Santoro, the Section Editor and the three anonymous referees are gratefully acknowledged for helpful comments on earlier drafts. The author is entirely responsible for any errors that remain. Special thanks are offered to Heidi Kempinski for overall support.

\section{References}

Adams, M. O., \& Osho, G. S. (2006). Drug company profits in the United States: are they excessive? Evidence from public administration perspectives. Journal of Business \& Economics Research, 4(2), 85-90.

\footnotetext{
18 See De George (2005, pp. 251-252) for a discussion of how frequently the industry relies on this defense.
} 
Almashat, S., Preston, C., Waterman, T., \& Wolfe, S. (2010). Rapidly increasing criminal and civil monetary penalties against the pharmaceutical industry: 1991 to 2010. http://www.citizen.org/ documents/rapidlyincreasingcriminalandcivilpenalties.pdf.

Angell, M. (2004). The truth about drug companies. New York: Random House.

Angell, M. (2008). Industry-sponsored clinical research: A broken system. Journal of the American Medical Association, 300(9), 1069-1071.

Armstrong v. United States, 364 U.S. 40. (1960). Supreme Court of the United States. http://laws.findlaw.com/us/364/40.html.

Arrow, K. (1963). Uncertainty and the welfare economics of medical care. The American Economic Review, 53(5), 941-973.

Bale, H. E. (1998). The conflicts between parallel trade and product access and innovation: the case of pharmaceuticals. Journal of International Economic Law, 1, 637-653.

Banerjee, A. (2006). Who has responsibility for access to essential medical drugs in the developing world? Ethics and Economics, $4(2), 1-23$.

Baron, J. (1998). Judgment misguided: Intuition and error in public decision making. New York: Oxford University Press.

Baron, J., \& Spranca, M. (1997). Protected values. Organizational Behavior and Human Decision Processes, 70(1), 1-16.

Berenson, A. (2006, February 15). A cancer drug shows promise, at a price that many can't pay. The New York Times. http://www.ny times.com/2006/02/15/business/15drug.html?pagewanted=all.

Bombardier, C., Laine, L., Reicin, A., Shaprio, D., Burgos-Vargas, R., Davis, B., et al. (2000). Comparison of upper gastrointestinal toxicity of rofecoxib and naproxen in patients with rheumatoid arthritis. The New England Journal of Medicine, 343(21), $1520-1528$.

Bresalier, R. S., Sandler, R. S., Quan, H., Bolognese, J. A., Oxenius, B., Horgan, K., et al. (2005). Cardiovascular effects associated with rofecoxib in a colorectal adenoma chemoprevention trial. The New England Journal of Medicine, 352(11), 1092-1102.

Brody, H. (2007). Hooked: Ethics, the medical profession, and the pharmaceutical industry. Lanham: Roman \& Littlefield.

Burke, E. (1790/1987). Reflections on the revolution in France (J. G. A. Pocock, Trans.). Indianapolis: Hackett.

Carroll, A. B. (1999). Corporate social responsibility: Evolution of a definitional construct. Business \& Society, 38(3), 268-295.

Chang, P. L. (2006). Who's in the business of saving lives? Journal of Medicine and Philosophy, 31, 465-482.

Chitemerere, C. (2011). Pharmaceutical sector profile: Zimbabwe (D. Hubbard, Ed.). Vienna: United Nations Industrial Development Organization (UNIDO). http://www.unido.org/index.php?id= 1001014.

Choo, C. W. (2008). Organizational disasters: Why they happen and how they may be prevented. Management Decision, 46(1), $323-345$.

Clark, J. (2003). A hot flush for big pharma. British Medical Journal, 327(7411), 400.

Cockburn, I., \& Henderson, R. (1996). Public-private interaction in pharmaceutical research. Proceedings of the National Academy of Sciences of the United States of America, 93, 12725-12730.

Cutler, D. M., Rosen, A. B., \& Vijan, S. (2006). The value of medical spending in the United States, 1960-2000. New England Journal of Medicine, 355, 920-927.

De George, R. T. (2005). Intellectual property and pharmaceutical drugs: An ethical analysis. Business Ethics Quarterly, 15(4), 549-575.

Dorfler, V., \& Ackermann, F. (2012). Understanding intuition: The case for two forms of intuition. Management Learning, 43(5), 545-564.

Durkheim, E. (1912/1995). The elementary forms of religious experience (K. E. Fields, Trans.). New York: The Free Press.
The Economist. (2012, November 6). The drug industry doesn't work. http://www.economist.com/blogs/babbage/2012/11/qa-ben-golda cre (Reprinted by permission, (CThe Economist Newspaper Limited, London).

Experts in Chronic Myeloid Leukemia. (2013). The price of drugs for chronic myeloid leukemia (CML) is a reflection of the unsustainable prices of cancer drugs: from the perspective of a large group of CML experts. Blood, 121(22), 4439-4442.

Fan, S., \& Rao, N. (2003). Public spending in developing countries: Trends, determination, and impact. Environment and Production Technology Division Discussion Paper No. 99. Washington, DC.

Fiske, A. P. (1992). The four elementary forms of sociality: Framework for a unified theory of social relations. Psychological Review, 99(4), 689-723.

Fiske, A. P., \& Tetlock, P. E. (1997). Taboo trade-offs: Reactions to transactions that transgress the spheres of justice. Political Psychology, 18(2), 225-297.

Fortune Magazine. (2011). 2011 Fortune 500. http://money.cnn.com/ magazines/fortune/fortune500/2011/full_list/.

Greenwald, D. E. (1973). Durkheim on society, thought and ritual. Sociological Analysis, 34(3), 157-168.

Greve, J. (2008). Healthcare in developing countries and the role of business: A global governance framework to enhance the accountability of pharmaceutical companies. Corporate Governance, 8(4), 490-505.

Haidt, J. (2001). The emotional dog and its rational tail: A social intuitionist approach to moral judgement. Psychological Review, 108(4), 814-834.

Hardwig, J. (1985). Epistemic dependence. The Journal of Philosophy, 82(7), 335-349.

Harris, G. (2004). Drug companies seek to mend their image. The New York Times. http://www.nytimes.com/2004/07/08/business/ drug-makers-seek-to-mend-their-fractured-image.html?pagewan ted $=$ all \&src $=$ pm.

Hasan, S., \& Wanyanga, W. (2010). Pharmaceutical sector profile: Kenya (D. Hubbard, Ed.). Vienna: United Nations Industrial Development Organization (UNIDO). http://www.unido.org/ index.php?id=1001014.

Herper, M. (2012, February 10). The truly staggering cost of inventing new drugs. Forbes. http://www.forbes.com/sites/mat thewherper/2012/02/10/the-truly-staggering-cost-of-inventingnew-drugs/.

Hilts, P. J. (2003). Protecting America's health. New York: Alfred A. Knopf.

Hsieh, N. (2008). Incommensurable values. In E. N. Zalta (Ed.), The Stanford encyclopedia of philosophy. http://plato.stanford.edu/ archives/fall2008/entries/value-incommensurable/.

Hume, D. (1739/1985). A treatise of human nature. New York: Penguin.

Jeske, D. (2008). Special obligations. In E. N. Zalta (Ed.), The Stanford encyclopedia of philosophy. http://plato.stanford.edu/ archives/fall2008/entries/special-obligations/.

Kaiser. (2005). Views on prescription drugs and the pharmaceutical industry. Kaiser Family Foundation Health Poll Report Survey. http://www.kff.org/healthpollreport/feb_2005/index.cfm.

Kanavos, P., Costa-i-Font, J., Merkur, S., \& Gemmill, M. (2004). The economic impact of pharmaceutical parallel trade in European Union member states: A stakeholder analysis. LSE Health and Social Care Special Research Paper. http://archives.who.int/ prioritymeds/report/append/829Paper.pdf.

Karha, J., \& Topol, E. J. (2004). The sad story of Vioxx, and what we should learn from it. Cleveland Clinic Journal of Medicine, 71(12), 933-939.

Koehler, J. J., \& Gershoff, A. D. (2003). Betrayal aversion: When agents of protection become agents of harm. Organizational Behavior and Human Decision Processes, 90, 244-261. 
Koroneos, G. (2009). Fixing Pfizers rep: An interview with Kathryn Metcalfe. http://www.pharmexec.com/pharmexec/article/article Detail.jsp?id=587895

Koski, E. G. (2005). Renegotiating the grand bargain. In M. A. Santoro \& T. M. Gorrie (Eds.), Ethics and the pharmaceutical industry (pp. 393-403). New York: Cambridge University Press.

Lehman, B. (2003). The pharmaceutical industry and the patent system. http://users.wfu.edu/mcfallta/DIR0/pharma_patents.pdf.

Leisinger, K. M. (2005). The corporate social responsibility of the pharmaceutical industry: Idealism without illusions and realism without resignation. Business Ethics Quarterly, 15(4), 577-594.

Lewis, N. A., \& Pear, R. (1994, March 07). U.S. drug industry fights reputation for price gouging. The New York Times. http://www. nytimes.com/1994/03/07/us/us-drug-industry-fights-reputationfor-price-gouging.html?pagewanted $=$ all $\&$ src $=$ pm.

Light, D. W., \& Warburton, R. (2012). The costly myths of pharmaceutical R\&D. http://www.pharmamyths.net/files/Pharm_ R_and_D_-_Costly_Myths_2012.pdf.

Maitland, I. (2002). Priceless goods: How should life-saving drugs be priced? Business Ethics Quarterly, 12(4), 451-480.

Maynard, A., \& Bloor, K. (2003). Trust and performance management in the medical marketplace. Journal of the Royal Society of Medicine, 96, 532-539.

McGraw, A. P., Schwartz, J. A., \& Tetlock, P. E. (2011). From the commercial to the communal: Reframing taboo trade-offs in religious and pharmaceutical marketing. Journal of Consumer Research, 39, 157-173.

Merck. (2004). Merck announces voluntary worldwide withdrawal of VIOXX. News Release, White House Station, NJ.

Mill, J. S. (1861/2007). Utilitarianism. Mineola: Dover.

Morel, C. M. (2003). Neglected diseases: Under-funded research and inadequate health interventions. European Molecular Biology Organization Reports, 4, S35-S38.

Moynihan, R., Heath, I., \& Henry, D. (2002). Selling sickness: The pharmaceutical industry and disease-mongering. British Medical Journal, 324, 886-891.

Nayyar, G. M. L., Breman, J. G., Newton, P. N., \& Herrington, J. (2012). Poor-quality antimalarial drugs in southeast Asia and sub-Saharan Africa. The Lancet Infectious Diseases, 12(6), 488-496.

Pillay, N. (2008). Right to health and the Universal Declaration of Human Rights. The Lancet, 372(9655), 2005-2006.

Porter, M. E., \& Kramer, M. R. (2006, December). Strategy \& society: The link between competitive advantage and corporate social responsibility. Harvard Business Review, 84, 78-92.

PricewaterhouseCoopers. (2006). Recapturing the vision-Restoring trust in the pharmaceutical industry by translating expectations into actions. http://www.pwc.com/gx/en/forms/download-anelectronic-version-of-recapturing-the-vision-restoring-trust-inthe-pharmaceutical-industry-by-translating-expectations-intoactions.jhtml.

Pyke, S., Julious, S. A., Day, S., O’Kelly, M., Todd, S., Matcham, J., et al. (2011). The potential for bias in reporting of industrysponsored clinical trials. Pharmaceutical Statistics, 10(1), 74-79.

Raz, J. (1986). The morality of freedom. New York: Oxford University Press.

Reisel, W. D., \& Sama, L. M. (2003). The distribution of life-saving pharmaceuticals: Viewing the conflict between social efficiency and economic efficiency through a social contract lens. Business and Society Review, 108(3), 365-387.

Resnik, D. B. (2001). Developing drugs for the developing world: An economic, legal, moral, and political dilemma. Deveoping World Bioethics, 1(1), 11-32.
Robinson, P. H., \& Kurzban, R. (2007). Concordance and conflict in intuitions of justice. Minnesota Law Review, 91, 1829-1907.

Robinson, P. H., Kurzban, R., \& Jones, O. D. (2007). The origins of shared intuitions of justice. Vanderbilt Law Review, 60(6), $1633-1688$.

Rugumambaju, S., \& Kutyabami, P. (2010). Pharmaceutical sector profile: Uganda (D. Hubbard, Ed.). Vienna: United Nations Industrial Development Organization (UNIDO). http://www. unido.org/index.php?id=1001014.

Sampat, B. N., \& Lichtenberg, F. R. (2011). What are the respective roles of the public and private sectors in pharmaceutical innovation? Health Affairs, 30(2), 332-339.

Santoro, M. A. (2005). Introduction: Creating a sustainable path for the twenty-first century pharmaceutical industry. In M. A. Santoro \& T. M. Gorrie (Eds.), Ethics and the pharmaceutical industry (pp. 1-5). New York: Cambridge University Press.

Sauer, H. (2011). Social intuitionism and the psychology of moral reasoning. Philosophy Compass, 6(10), 708-721.

Shirley, D. A., \& Langan-Fox, J. (1996). Intuition: A review of the literature. Psychological Reports, 79, 563-584.

Singer, P. (1972). Famine, affluence, and morality. Philosophy \& Public Affairs, 1(3), 229-243.

Spinello, R. A. (1992). Ethics, pricing and the pharmaceutical industry. Journal of Business Ethics, 11, 617-626.

Taurel, S. (2005). The campaign against innovation. In M. A. Santoro \& T. M. Gorrie (Eds.), Ethics and the pharmaceutical industry. New York: Cambridge University Press.

Tetlock, P. E. (2002). Social functionalist frameworks for judgment and choice: Intuitive politicians, theologians, and prosecutors. Psychological Review, 109(3), 451-471.

Tetlock, P. E., Kristel, O. V., Elson, S. B., Green, M. C., \& Lerner, J. S. (2000). The psychology of the unthinkable: Taboo trade-offs, forbidden base rates, and heretical counterfactuals. Journal of Personality and Social Psychology, 78(5), 853-870.

The New York Times. (1994). Taxpayers may be paying twice for some drugs. http://www.nytimes.com/1994/07/12/science/tax payers-may-be-paying-twice-for-some-drugs.html.

United Nations. (2008). UN General Assembly: the right to health/ note by the Secretary-General, 11 August 2008, A/63/263.

Wambebe, C., \& Ochekpe, N. (2011). Pharmaceutical sector profile: Nigeria. Vienna: United Nations Industrial Development Organization (UNIDO). http://www.unido.org/index.php?id=1001014.

Weber, L. J. (2001). Business ethics in healthcare: Beyond compliance. Bloomington: Indiana University Press.

Wolf, S. (2009). Moral obligations and social commands. In S. Newlands \& L. M. Jorgensen (Eds.), Metaphysics and the good: Themes from the philosophy of Robert Merrihew Adams (pp. 343-367). New York: Oxford University Press.

Zucker, L. G. (1987). Institutional theories of organization. Annual Review of Sociology, 13, 443-464.

Zycher, B., \& DiMasi, J. A. (2008). The truth about drug innovation: Thirty-five summary case histories on private sector contributions to pharmaceutical science. Medical Progress Report (Vol. 6). Center for Medical Progress at the Manhattan Institute. http:// www.unz.org/Pub/PolicyArchive-2008jun-00009?View=PDF.

Zyzik, R. (2011). Normativity and moral psychology: Social intuitions model and the world without normative moral rules? In J. Stelmach \& B. B Brożek (Eds.), Studies in the philosophy of law: The normativity of law (pp. 213-226). Kraków: Copernicus Center Press. 